DOI: doi.org/10.21009/IJLECR.052.18

Received: 5 June 2019

Revised: 10 June 2019

Accepted: 14 August 2019

Published: 31 December 2019

\title{
THE CALLA-BASED ELENA MODEL FOR LINGUISTICS: DOES IT WORK?
}

\author{
Frimadhona Syafri ${ }^{1, a)}$, Zainal Rafli ${ }^{2, b)}$ \\ Universitas Negeri Semarang, Indonesia ${ }^{1)}$. Universitas Negeri Jakarta, Indonesia ${ }^{2)}$ \\ frimadhona@mail.unnes.ac.id ${ }^{\text {a) }}$,Zainal.rafli@unj.ac.id ${ }^{\text {b) }}$
}

\begin{abstract}
This paper is aimed to describe the implementation of the CALLA-based ELENA model for introduction to linguistics course in the English Department of Universitas Negeri Semarang (UNNES). The research was conducted through descriptive analysis. The analysis of data is the impact of the implementation of the model for the Introduction to linguistics course. Data of the study were collected through observation, questionnaires, and tests. The result of the study shows that using the model can provide the learners' comprehension in learning linguistics concepts. Further, that model has emerged as one of the alternative modes of instruction delivery in the concept of linguistics. This research finding can be used to review current online learning model trends and to explore potential research directions.
\end{abstract}

Keywords: Descriptive analysis study, Cognitive Academic Language Learning Approach (CALLA), Electronic Learning Aid (ELENA)

Linguistics concepts should be mastered by English Department learners at UNNES. It will support learners' language competence. Introduction to linguistics course, besides, providing a basis for further study in linguistics and sufficient insight into the field of linguistics for those interested in language disciplines (Albashtawi, Jaganathan, \& 2016). Understanding of linguistic concepts becomes the main foundation for learners to study linguistic-oriented courses for higher levels. Unfortunately, most of the learners have not caught up the linguistics competence as a requirement. They seemed unmotivated to be involved actively in the learning process and it influenced their learning performance. However, based on preliminary studies, it was found that understanding the concept of linguistics is hard. Similarly, Widyastuti and Andriyanti (2010) stated that learning linguistic terms is an obstacle for learners in understanding the basic concepts of linguistics found in various linguistic branches. It has to be considered how to solve the problem by using available facilities on the campus.

Nowadays, using the internet in teaching-learning is becoming a normal extension. The use of ICT in education has been a challenge for learners. The shift in learner expectations, changing demographics of learners, and the rapid development of subject knowledge forms challenges to universities (Ashit Kumar Dutta, Al-Adhaileh Mosley, \& Mohammad Mobin Akhtar, 2011). To create an e-learning system is needed an LMS that is available to work and share ideas. As stated by Tucker, Wycoff, and Green (2016), LMS is a network software application based on the technology used to plan, implement, and assess the learning process. In essence, LMS is a system that strengthens learning instructors by creating and delivering lesson content, monitoring learners' 
participation online, and assessing learners' performance Simonson et al. (2019).

ELENA is an LMS that can be used by lecturers at UNNES to create individual courses, send assignments, conduct discussions with learners asynchronously, organize quizzes and tests, and direct learners' progress in the learning process. However, ELENA as a technical tool is an LMS that is in line with learners' requirements. The efficacy of ELENA as e-learning was questioned by some academic staff in UNNES. They regarded ELENA may not be different from other technological innovative strides that have been presented previously in the education field but failed to produce a significant impact on the teaching and learning of the subjects. Moreover, it would be discovered that much is still needed to be done to ensure that the advantage of ELENA as e-learning technology is optimally exploited. It has been described that the existence of ELENA activities provides the benefits obtained by instructors. The instructor will more easily carry out material and model through the updated teaching model following the demands of scientific developments that occur. Furthermore, it can efficiently control learners in learning activities Edosomwan (2016).

To improve the teaching-learning process, online activities also can be used to either enhance learning undertaken in the classroom, or they can serve as a basic introduction to topics before they are covered in more depth in class. For e-learning with an online internet-based approach provides more easily developed in the online mode of teaching. For learners, they do not only learn from the lecturers but also learn from many sources unlimitedly. Consequently, they can increase their knowledge beyond what just the lecturer had given. The online learning process will be meaningful if done with one approach. One approach that can be used is CALLA. The rationale of using CALLA is a theoretical framework of CALLA, that is learning is an active and dynamic process; students can take control over their own learning and develop independent learning skills; and it uses three strategies (cognitive, metacognitive, social/affective). Considering the utility of elearning, the writer combined CALLA and ELENA to be applied in the introduction to the linguistics course. The use of the CALLA-based ELENA model for learners to comprehend the concepts of linguistics is very essential. It provides a learning revolution in the educational system through online learning and tap benefits to the effective teaching and learning method.

\section{Linguistics}

Linguistics is one branch of science that studies all aspects related to language. Linguistics is the basic science to explore the field of language studies and other sciences Fromkin, Rodman, and Hyams (2011). This statement implies the importance of linguistics in various aspects of the scientific field. Linguistics is a foundation of language which is the basis of science. Linguistics is descriptive, not prescriptive that must be used.

The science of language is known as linguistics. It includes what is generally distinguished as descriptive linguistics and historical linguistics. Linguistics is now a highly technical subject; it embraces, both descriptively and historically, such major divisions as phonetics, grammar (including syntax and morphology), semantics, and pragmatics, dealing in detail with these various aspects of language. Moreover, Linguistics is related to other fields of study, such as Psycholinguistics, Stylistics, Sociolinguistics, Anthropological Linguistics, Philosophical Linguistics, Applied Linguistics, and Computational Linguistics. The scope of linguistics looks as follows $\mathrm{Oz}(2014)$. 


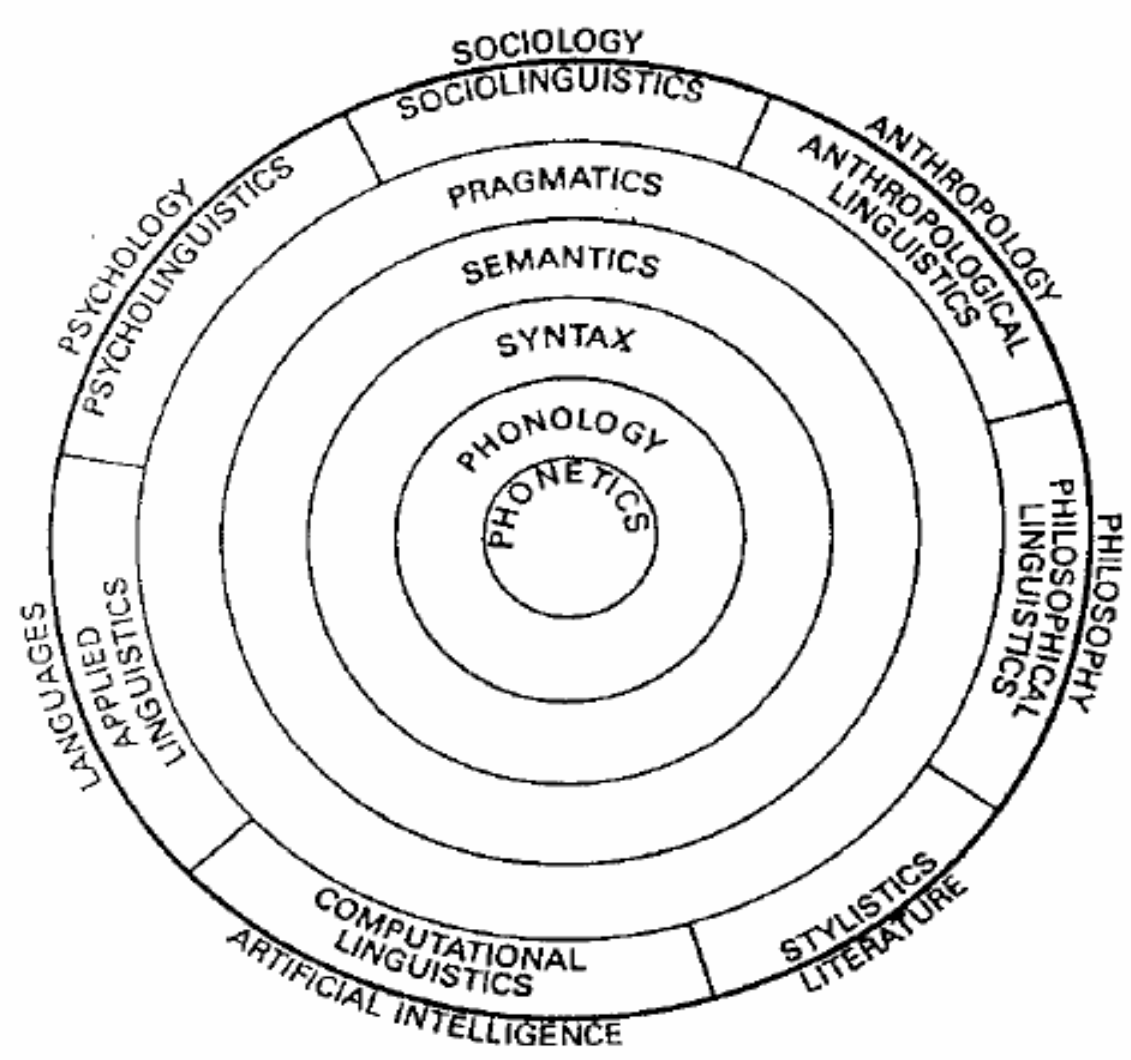

Figure 1. Scope of linguistics

Linguistics is a science that has a reciprocal relationship with other sciences, especially social science and humanity. As explained by (Albashtawi et al., 2016; Haspelmath \& Sims, 2010), the branch of linguistics is divided into five core branches traditionally, namely phonetics, phonology, morphology, syntax, and semantics. Along with the times, some branches of Linguistics emerged such as pragmatics, stylistics, dialectology. Furthermore, Linguistics engages in interest in other fields of science so that other branches of Linguistic science (interdisciplinary approaches) emerge such as sociolinguistics, anthropological linguistics, biolinguistics, clinical linguistics, computational linguistics, ethnolinguistics, philosophical linguistics, and psycholinguistics, (Albashtawi et al., 2016)

Introduction to Linguistics course is a prerequisite course for English Language Education learners UNNES. After completing this course, the learners are expected to have adequate knowledge of the nature and characteristics of language, linguistic research methodology, the history of the development of linguistics, the linguistics scholars and the dichotomy of language studies (linguistics) as the basis for language learning. The course has a purpose, namely (a) this course allows learners to understand linguistics as a science and possess basic knowledge of the nature of language, its function, and its relationship with other sciences; (b) learners have a basis for further study in the field of linguistics; (c) learners in the main field of linguistics have sufficient insight in other fields of science. Judging from the objectives of this linguistic course, learners possess basic knowledge and have analytical competencies as skills to make observations, research, and assessment of other fields of science seen from the eyes of Linguistics Haspelmath and Sims (2010).

The description above describes that Introduction to Linguistics is a crucial subject in the field of language study. Knowledge about Linguistics is not only limited to concepts and terms 
understanding. Introduction to Linguistics learning also emphasizes that learners have an understanding and skill in carrying out analysis in observing the phenomena of the language around them. That is, understanding of Linguistics is not only seen from the structure of the language but also its involvement with language learning which is seen critically in the social and cultural fields. Thus, an appropriate linguistic learning approach is needed that can stimulate learners' competence both in terms of understanding and skills in conducting language analysis.

Learning linguistics means learning academic terms in the language. It reflects in academic reading as discussed by Sima Sengupta (2002). It is a purposeful and critical reading of lengthy academic reading texts for completing the study of specific subject areas. The nature of academic reading texts poses different kinds of difficulties that hinder our learners from understanding the meaning of the text. Shen, Kwan, and Chai (2013) have investigated the difficulties of the academic reading met by the EFL learners at the undergraduate level. The results have indicated that academic reading difficulties are attributed to the deficiency in their language ability and their inability to comprehend content material. Vocabulary has been perceived to be the primary challenge especially when learners come to reading in their content-areas.

Moreover, learners' reading strategies and needs are variations across disciplines, and thus most learners have shown a desire for greater support (e.g., highlighting key points, and preteaching terminologies, sentence structures, grammar, and reading strategies) (W, Strong, et.al, 2002). Based on those problems, the learners need to be familiar with some strategies to support their comprehension in learning linguistics as an academic language.

\section{CALLA}

According to Chamot and O'Malley (1994), CALLA is an instructional model developed to meet the academic needs of learners in learning English as a second language as well as a foreign language. This CALLA incorporates three components and instructional objectivity in its learning design, namely topics from subject matter content, the development of academic language skills (Academic Language Functions), and learning strategies that combine content and language acquisition.

In their Handbook of CALLA, Chamot and O'Malley (1994) describe the types of learning strategies used in this CALLA approach.

a) Metacognitive strategies: this strategy includes planning, monitoring, and evaluating learning activities, Nejad, Mahmoodi-Shahrebabaki, and Teaching (2015)

b) Cognitive strategies: strategies include exercising, organizing and elaborating knowledge, (K. \& Alharahsheh, 2015)

c) Social/affective strategies: learners learn the structure and function of language to practice in cooperative learning settings and obtain feedback from other learners effectively and coherence to communicate orally and in writing.

The important thing in teaching-learning strategies is the use of methods for strategy instruction, namely how to introduce certain strategies to learners, influence the use of these strategies, maintain their use and transfer these strategies at the next opportunity. Following is the strategy instruction framework presented by Chamot and O'Malley. 


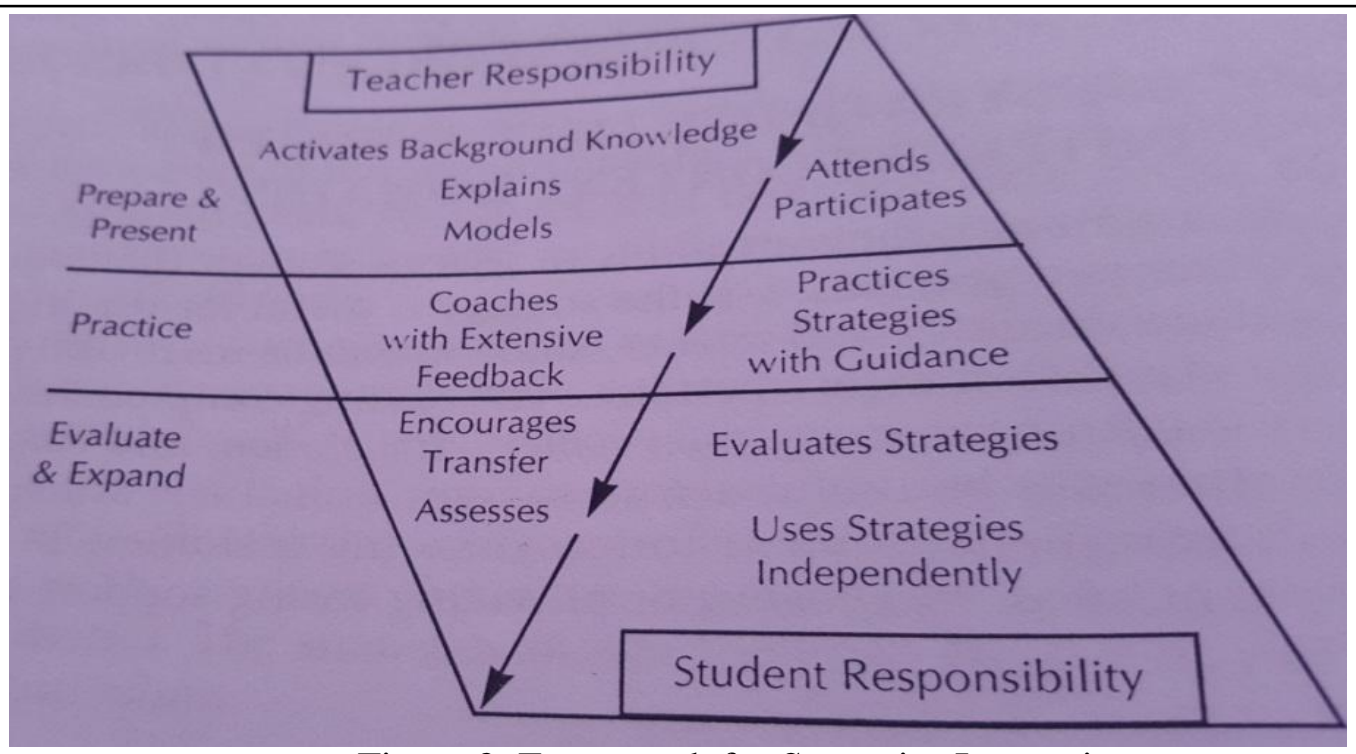

Figure 2. Framework for Strategies Instruction

These three learning strategies form the basis of the CALLA approach. The ability of learners to use metacognitive strategies appropriately train learners to do learning planning; monitor learners' understanding and production; and train how learners evaluate the learning objectives. Likewise, cognitive strategy abilities, learners are trained to manipulate material mentally (creating images or elaboration) and physically (doing a grouping of material to be studied or taking notes). Finally, social/affective strategy capabilities, abilities that are used to interact with one another to help to learn such as cooperative learning.

Chamot and O'Malley (1994) also explained the CALLA approach which consisted of five phases, namely preparation, presentation, practice, evaluation, and expansion. Each phase has a connection between one phase and another phase. For example, preparation is the phase of preparing learners to identify and reflect on previous knowledge related to the topic of learning. This means that the lecturer gives an introduction to the learning objectivity, introduces new vocabulary, and concrete experiences that are connected with the learners' prior knowledge. Furthermore, in the presentation phase, lecturers explain new information, skills, and learning strategies, information is presented through various methods to accommodate different learners learning styles. Then the practice phase, learners actively practice new concepts, learning skills and strategies such as cooperative learning activities. Furthermore, in the evaluation phase, learners practice individually and cooperatively towards self-evaluation. Finally, the expansion phase, learners integrate what is learned into the knowledge framework; compile and re-select prior knowledge as needed; apply knowledge, skills, and study situations in the context of real-life, Adigüzel and Gürses (2013).

\section{ELENA}

The development of technology has penetrated all aspects of life including the world of education. The empowerment of the internet as a medium in the delivery of teaching material has become a trend in the last few decades so that a new term is called e-learning. The use of the "e" prefix in some terms indicates the involvement of "electronic" in an activity. To provide services in lecture activities, MOODLE can be presented on a mobile basis using a mobile learning platform, Simonson, Zvacek, and Salmadino (2019). Besides that, the development of extensions through adding plug-ins is also needed to provide lecture services as needed. UNNES has provided ELENA as a mobile learning platform. 


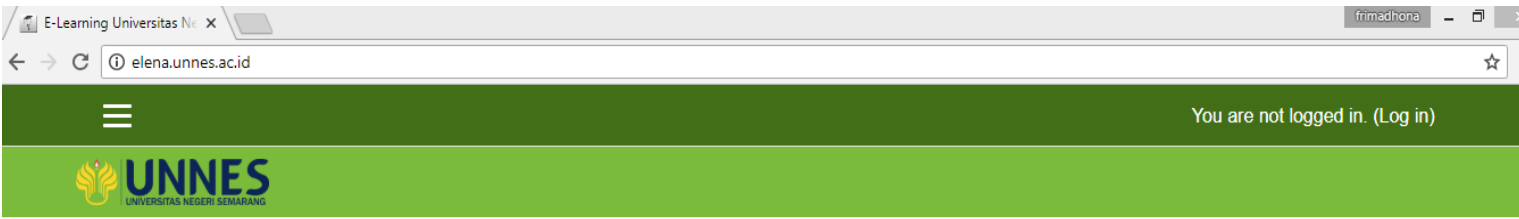

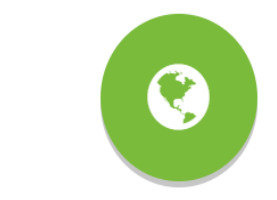

MULTILINGUAL

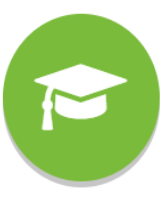

ONLINE STUDY

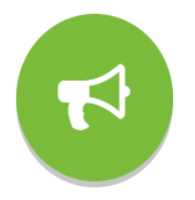

COMMUNITY SUPPORT

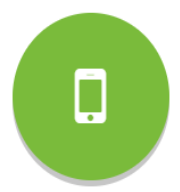

RESPONSIVE DESIGN

Figure 3. The start page of the ELENA site

ELENA is the abbreviation from Electronic Learning Aid. It is an e-learning site developed MOODLE of UNNES to support academic activities. In the beginning, its appearance in 2009, this e-learning site was named ILMO which was later renamed become ELENA. This ELENA learning site can be accessed via the address http://elena.unnes.ac.id.

To create an e-learning system is needed an LMS that is available to work and share ideas. As stated by Tucker, Wycoff, and Green (2016), LMS is a network software application based on the technology used to plan, implement, and assess the learning process. In essence, LMS is a system that strengthens learning instructors by creating and delivering lesson content, monitoring learners' participation online, and assessing learners' performance Simonson et al. (2019); (W et al., 2002). ELENA is an LMS that can be used by a lecturer at UNNES to create individual courses, send assignments, conduct discussions with learners asynchronously, organize quizzes and tests, and direct learners' progress in the learning process.

\section{The CALLA-Based ELENA Model}

In the implementation of the CALLA-based ELENA model, several CALLA strategies are linked to online learning activities, such as CALLA-based online learning planning, application of CALLA stages, and monitoring of CALLA instructional implementation carried out using the features available at ELENA. For more detail, the following chart drawings describe the application of a combination of ELENA features that are by the stages and CALLA strategy. 


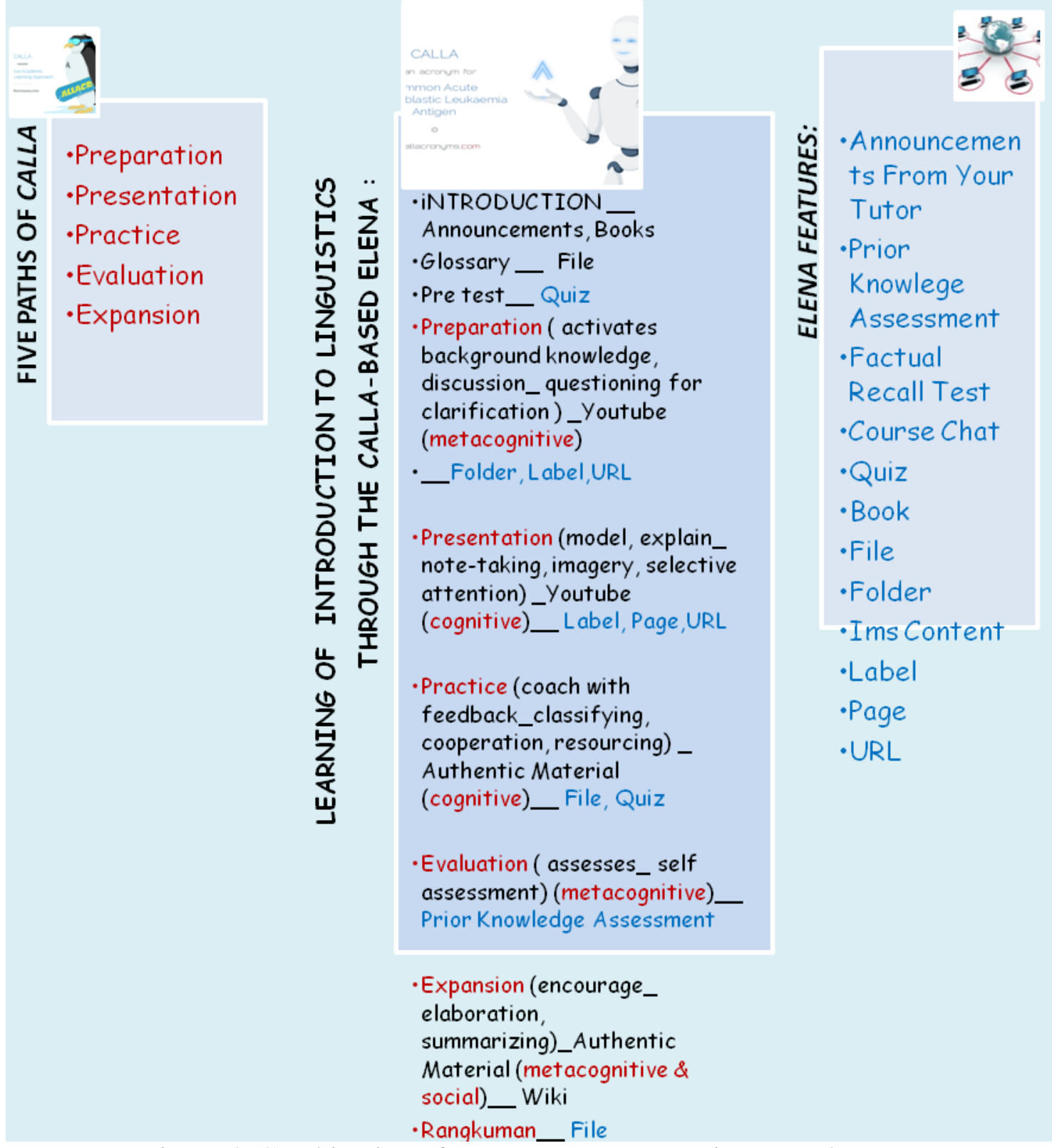

Figure 4. Combination of CALLA strategies and ELENA features

For this reason, some ELENA features are needed that are combined and adjusted to the characteristics of learning Introduction to linguistics and strategies contained in CALLA, namely:

a. Preparation is to develop metacognitive awareness and knowledge of students through activities: (1) discuss the strategies that have been used; (2) interviewing small groups about certain techniques that they do; (3) study the questionnaire regarding a particular strategy; and (4) interviewing students' way of thinking in doing assignments. ELENA features that are suitable for use are folder, label, URL

b. The presentation is teaching cognitive strategies to students by: (1) becoming a model of how to use certain techniques; (2) name certain techniques and refer to students how the strategy will help them learn the material; (3) explains when, how, and certain types of tasks are carried out according to the techniques they use. The appropriate ELENA features implemented are label, page, URL.

c. The practice that allows students to practice cognitive strategies with certain techniques through activities, such as cooperative learning, research projects, mathematics word problems, 
developing oral and written reports, analyzing literature, and process writing. The appropriate ELENA feature implemented is file, quiz.

d. Evaluation is developing a metacognitive strategy. Students can conduct self-evaluations such as (1) debriefing discussion after using strategies; (2) studying logs or journals so that students explain and evaluate the strategies used; (3) comparing student performance in completing assignments between strategies without using strategies; (4) checklists on the level of use of the technique; (5) creating a self-questionnaire regarding the techniques used in completing certain academic assignments; and (6) make a self-report about when students use certain techniques. The appropriate ELENA feature used is the Prior Knowledge Assessment.

e. Expansion which proves the use of CALLA strategies for new tasks through activities such as (1) creating a framework (scaffolding) to remind the use of the strategy; (2) strengthening the use of strategies independently; (3) report in front of the class to new assignments that have been successful and (4) discuss the application of strategies made by students to new assignments and contexts using authentic material. The appropriate ELENA features implemented are wikis, URLs, files.

\section{METHOD}

The study was conducted at the English Education Program, English Department, UNNES. Data of the study were collected through observation, questionnaires, and tests. The researcher observed students' activities during the online learning process. Then, the researcher delivered the questionnaire to get the students' responses to the implementation of the model. Last, the researcher and lecturer held a formative test to know students' linguistics comprehension. Besides, the analysis is to get the information about the impact of the implementation of the CALLA-based ELENA model for Introduction to linguistics related to the usefulness, ease of use and self-efficacy.

\section{RESULTS AND DISCUSSION}

Based on the preliminary studies conducted in the Introduction to Linguistics courses in the English Language Education program at UNNES, several obstacles were found in the implementation of Introduction to Linguistics course. These constraints include the demand for material understanding that is quite a lot both theoretically and practically and the imbalance of mastery of theory and practice competencies mastered by learners. The reason is the lack of innovation in learning models that can construct ideas and experiences of learners, difficulties in understanding terms that are unfamiliar to learners, and lack of time in delivering material thoroughly which should be done by optimizing learner independence without waiting for the presence of instructors. They cause unmotivated learners to involve actively in the learning process. The statement is in line with the opinion expressed by Alghail, Abdullah, Mahfoodh, and Hassan (2016) that five things are most difficult for International learners in academic reading (textbooks), namely: (1) making relevant summary notes; (2) paraphrase using your own words; (3) interpret difficult words; (4) identifying ideas or examples; and (5) arranging time to complete academic reading material. This opinion was confirmed by Satirani (2018) that learners have low reading skills caused by several things, which include: (1) difficulty in remembering the information they just read; (2) reading material that is not familiar to learners; (3) it takes a lot of time to finish reading; (4) unusual reading materials and complex grammatical texts; and (5) sentences that are too long and complex.

Based on the research results above, it is known English study program learners who take the introduction to linguistics courses are aged 20 to 25 years. Judging from the age of these learners, they are adults who learn on their consciousness. Adult learning is independent learning that is aligned with the needs and interests of learners and provides satisfaction. Experience is the 
most important source of learning for adult learning processes based on observation and experience, as well as the desire to regulate themselves into the needs of adults. Therefore, lecturers are facilitators rather than transferring knowledge to learners. In line with what was delivered by (W, et al., 2002) that adult learning is learning based on experience, both consciously and unconsciously and there is transformation, self-regulation, and actualization. Therefore, learning in class which only comes from the lecturer is not sufficient for learners to explore their potential and ability to apply the concepts of linguistics. For this reason, adequate infrastructure is needed and supports their ability to learn independently.

The availability of adequate facilities and infrastructure at UNNES certainly provides a high enough opportunity for more optimal use and management of learning. In this regard, they need a learning model that can help them to develop their competencies. Efforts that can be made to overcome the obstacles above are using the right learning approach and utilizing the available infrastructure. One of the efforts made was the development of the CALLA-based ELENA model on the Introduction to Linguistics course. The research on the development of this learning model was developed and implemented in several stages, namely arranging learning plans, implementing learning, and testing the effectiveness of the learning, (Lopes, 2014).

In the learning planning stage, the lesson plan has an important role. The lesson plan refers to the Indonesian government policy related to learning competencies and learning objectives of Introduction to Linguistics course that should be achieved. It also describes methods, learning activities, learning assessment, teaching material, techniques and steps of learning carried out in each meeting. In this study, the subject chosen from the Introduction to Linguistics is Morphology. $(\mathrm{Oz}, 2014)$ states that, "Morphology, therefore, is the simply a term for that branch of linguistics which is concerned with the 'form of words' in different uses and contraction". The object of morphology is a term that correlates with the formation of words. Word formation is the creation of a new word, sometimes it changes the word's meaning and class. While, Haspelmath and Sims (2010) stated that "Morphology is the study of morphemes, their variation, and their combination in words".

The results of the planned learning plan are tested for feasibility which will later be used as a guideline for learning activities in the implementation phase which is carried out in the next stage. 


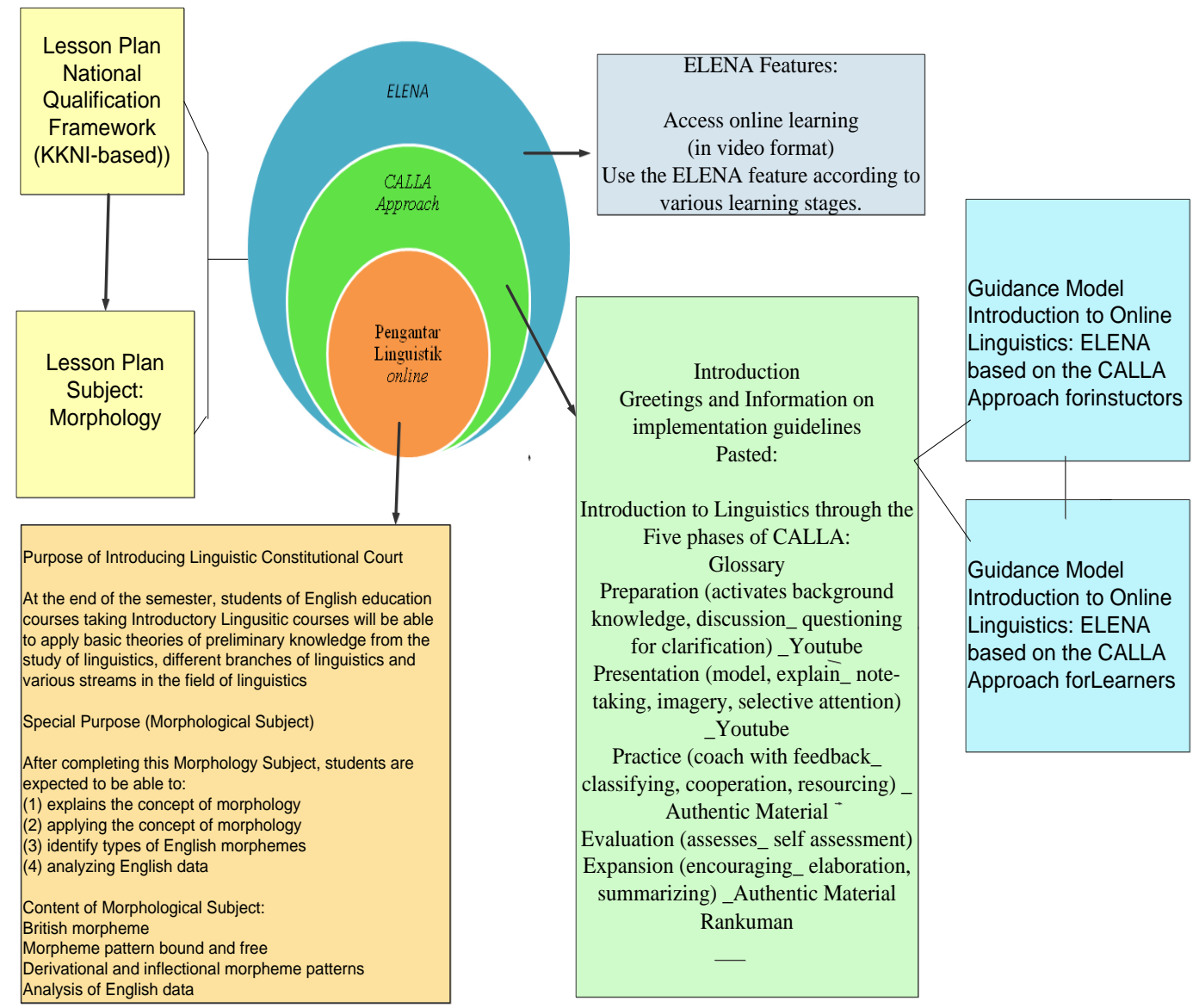

Figure 5. The CALLA-Based ELENA Model

The implementation phase is carried out by conducting experiments using the CALLAbased ELENA model on the Introduction to Linguistics course. In addition to exposing the ability of learners to apply linguistic concepts, learners are allowed to carry out exploration and independent learning through internet facilities that have been provided by UNNES such as ELENA.

The use of ELENA based on CALLA in Introduction to Linguistics encourages the score of learners. It describes from the pre-test and post-test. 


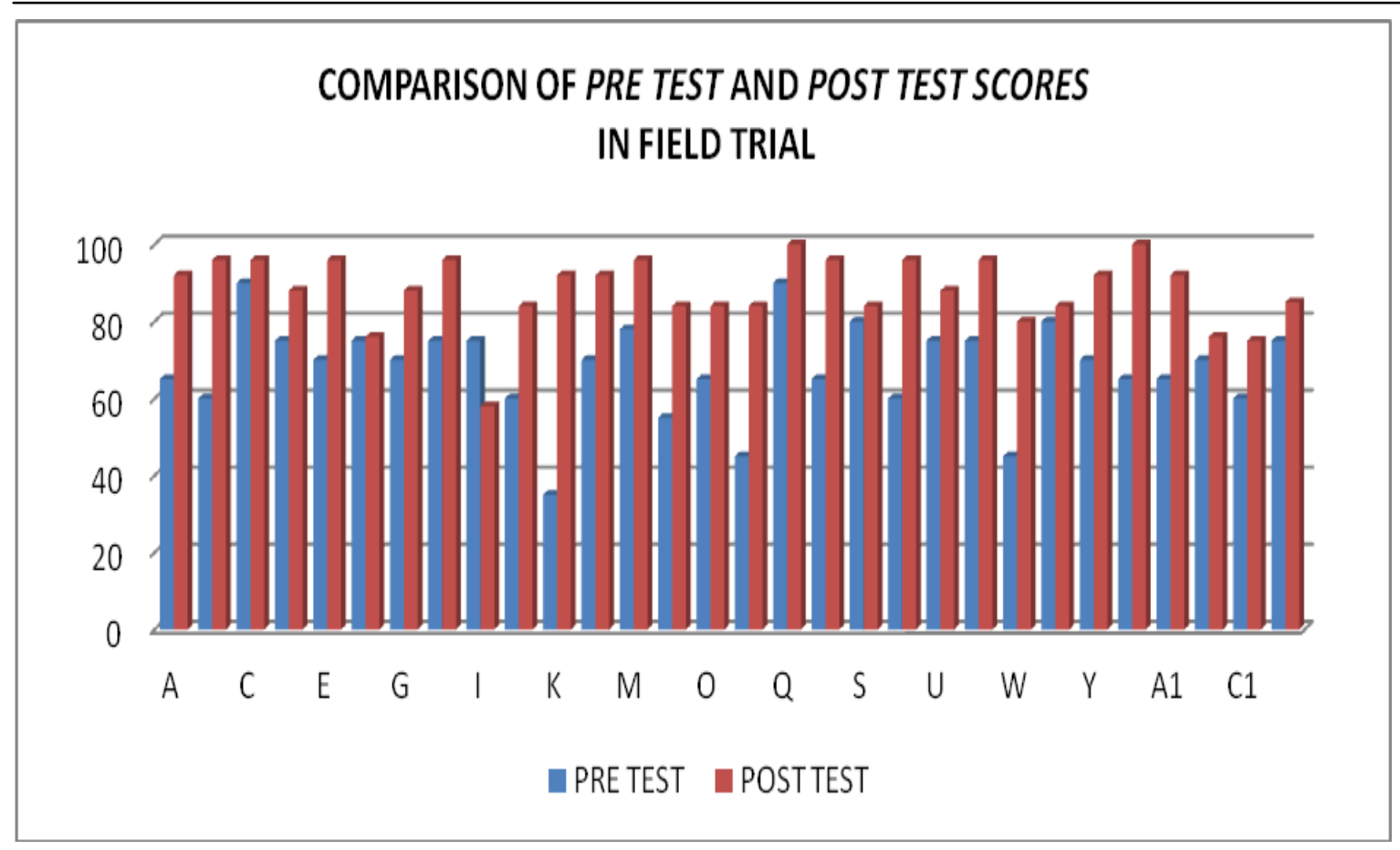

Figure 5. Comparison of Pre-Test and Post-Test in Field Trial

The comparison of the pre-test and post-test scores of the field trial group learners was also signed between the pre-test and post-test scores. Most field trial learners have post-test scores above 75. The comparison also shows that the implementation of learning activities can run well. Although in the chart above there is one learner (I) who has decreased from the pre-test 75 to the post-test 58 that does not affect the overall results. Judging from the average value, the average pretest value is 67 while the average value of the post-test is 89 .

The result of the research shows that the strategy of implementing ELENA as e-learning will be the best way for learners to be aware of new technology and willing to study in various concepts. The use of ELENA, new technology, should be used with an appropriate approach. It depends on the characteristics of the course Lu (2012). The use of an approach makes the teaching-learning process of e-learning will be meaningful. Moreover, the use of the CALLA-based ELENA model could enhance independent learning and autonomous learning for students, Chitashvili (2007). The management should upgrade and maintain the technology on campus to ensure ELENA as elearning could be useful to the learners. Related to this result showing that e-learning affects their self-efficacy especially in upgrading their knowledge and skills, (Edosomwan, 2016).

The learners' perceptions toward implementation CALLA-based ELENA in Introduction to Linguistics obtained through questionnaires. It proved that learners of group field trials in implementation of the CALLA-based ELENA in Introduction to Linguistics are positive. Nejad et al. (2015) note that there was also a significant positive relationship between the use of CALLA and the learners' reading comprehension performance. They argue that this practical learning model can be used wherever and whenever and the design of interactive learning to improve knowledge and apply the concepts of Linguistics to learning. It has been described that the existence of ELENA activities provides the benefits obtained by instructors.

The model of e-learning that strengthens and provides motivation to learners to learn independently and can improve their skills in applying linguistic concepts. This model enhances the learner to be an autonomous learner. As stated by Chitashvili (2007) that concept of autonomy involves self-confidence and autonomy; usage of individual learning strategies; It depends on 
learners willing to take responsibility for their learning; It is closely related to metacognitive strategies: planning, making decisions, monitoring, and evaluation

This model also supports government programs, particularly the Ministry of Research, Technology and Higher Education in promoting online learning in higher education. Circular from the Director-General of Institutional Science, Technology and Higher Education concerning Higher Education Clustering in 2010, where one indicator of its lateralization is online learning is a program that integrates the Directorate of Learning as the person responsible for implementing online learning programs through the Indonesian Online Learning System with Directorate of Institutional Development of the Higher Education Science and Technology responsible for higher education clustering programs. By making online learning one of the indicators of clustering, universities are encouraged to start active in carrying out online learning, Ashit Kumar Dutta, AlAdhaileh Mosley, and Mohammad Mobin Akhtar (2011).

\section{CONCLUSION}

The implementation of the CALLA-based ELENA model in the Introduction to Linguistics course is effective to enhance students' knowledge about the basic concepts of linguistics. In addition, this model can strengthen and motivate students to learn independently and be able to explore their knowledge and skills. The results of this study also received positive responses from students who used them, seen from the results of the completeness of student activities and the post-test scores that were better than the pretest scores.

\section{REFERENCES}

Adıgüzel, O. C., \& Gürses, M. Ö. (2013). Students' Opinions Regarding Reading Strategies Instruction Based on the Cognitive Academic Language Learning Approach. Turkish Online Journal of Qualitative Inquiry, 4(3).

Albashtawi, A. H., Jaganathan, P., \&, M. S. (2016). Linguistic Knowledge Aspects in Academic Reading: Challenges and Deployed Strategies by English-Major Undergraduates at a Jordanian Institution of Higher Education. Higher Education Studies, 6(3), 61-71.

Alghail, A., Abdullah, A., Mahfoodh, A., \& Hassan, O. (2016). Academic reading difficulties encountered by international graduate students in a Malaysian university. Issues in Educational Research, 26(3), 369.

Chamot, A. U., \& O'malley, J. M. (1994). The CALLA handbook: Implementing the cognitive academic language learning approach. New York: Addison-Wesley Publishing Company.

Chitashvili, N. (2007). The Concept of Autonomy in Second Language Learning. Education Science and Psychology, 11(2), 17-22.

Dutta, A. K., Mosley, A.-A., \& Akhtar, M. M. (2011). E-learning in Higher Education: Design and Implementation International Journal of Computer Science Issue, 8(4).

Simeon O. Edosomwan. (2016). Childhood Learning vs. Adulthood Learning: The Theory of Pedagogy and Andragogy. US-China Education Review A, 6(2). DOI:10.17265/2161$623 x / 2016.02 .004$

Ersoy, M. (2019). Information for Knowledge: A Case Study on Education Faculty Students' Internet-based Selective Learning Habits. Turkish Online Journal of Qualitative Inquiry, 90111. DOI:10.17569/tojqi.496012

Fromkin, V., Rodman, R., \& Hyams. (2011). An Introduction to language. 9th edition. Australia: Thomson.

Haspelmath, M., \& Sims, A. (2010). Understanding morphology. USA: Routledge.

K., O., \& Alharahsheh, A. (2015). The Effect of Using CALLA Instruction Strategies on 9th Grade Students' Writing Achievement and Satisfaction Journal of Literature. Languages, and 
Linguistics 15(12).

Lopes, A. P. (2014). Learning management systems in higher education. Turkish Online Journal of Qualitative Inquiry, 8(2), 5360-5365.

Qu, G., \& Lu, L. (2012). A Study on Blended Learning Assessment Methods for Laboratory Intensive Courses Teaching. International Journal of Information and Education Technology, 603-607. DOI:10.7763/ijiet.2012.v2.214

Mahmoodi-Shahrebabaki, M. (2015). Effects of Metacognitive Strategy Instruction on the Reading Comprehension of English Language Learners through the Cognitive Academic Language Learning Approach (CALLA). International Journal of Languages' Education, 1(Volume 6), 133-133. DOI:10.18298/ijlet.463

Oz, H. (2014). Morphological Awareness and Some Implications for English Language Teaching. Procedia - Social and Behavioral Sciences, 136, 98-103. DOI:10.1016/j.sbspro.2014.05.296

Shen, Y., Kwan, M.-P., \& Chai, Y. (2013). Investigating commuting flexibility with GPS data and 3D visualization: a case study of Beijing. China. Journal of Transport Geography, 32, 1-11. Retrieved from https://www.sciencedirect.com website.

Sima Sengupta, S. (2002). Developing Academic Reading At Tertiary Level: A Longitudinal Study Tracing Conceptual Change. the Reading Matrix, volume 2. No.1.

Simonson, M., Zvacek, S. M., \& Salmadino, S. (2019). Teaching and Learning at a Distance: Foundations of Distance Education 7th Edition.USA: IAP.

Tucker, C. R., Wycoff, T., \& Green, J. T. (2016). Blended Learning in Action: A Practical Guide toward Sustainable Change.USA: Corwin Press.

W, Strong, et.al. (2002). Reading for academic success: Powerful strategies for struggling, average, and advanced readers, Grades 7-12. In. USA: Corwin Press

Widyastuti, Susana dan Erna Andriyanti. (2010). Pengembangan Materi Pembelajaran Mandiri sebagai Upaya Peningkatan Pemahaman Konsep-konsep Dasar Linguistik dalam Mata Kuliah” Introduction to Linguistics". Jurnal Diksi. Vol.17 